\title{
(Re)Aprender a ensinar em tempos de Covid-19: discutindo os desafios na prática docente
}

\section{(Re)Learning to teach in Covid-19 times: discussing the challenges in teaching practice}

${ }^{1}$ Marcelo Borges Rocharochamarcelo36@yahoo.com.br

\begin{abstract}
RESUMO
Com o advento da Covid-19, do isolamento social e de medidas preventivas contra o novo coronavírus, foi necessário suspender as atividades presenciais em todo o mundo. Professores e estudantes migraram para a realidade online de forma que as aulas acontecessem em ambientes virtuais. Este contexto, fez com que muitos professores tivessem que re(aprender) a ensinar de modo remoto. Assim, esta pesquisa teve como objetivo investigar como os professores desenvolveram atividades pedagógicas, problematizando desafios e dificuldades enfrentados durante o processo de ensino-aprendizagem. Para tal, foi aplicado um questionário online para 145 professores com questões fechadas e abertas, sendo estas analisadas à luz da Análise de Conteúdo. Foi possível observar que dentre os principais desafios destacam-se a conexão, a apropriação das plataforma digitais e a falta de interesse dos alunos. Entretanto, mesmo diante disto, os professores buscaram formas de ultrapassar dificuldades para tornar o ensino remoto mais interativo, motivador e dinâmico.
\end{abstract}

Palavras-chave: Ensino remoto. Covid-19. Atividades pedagógicas.

\begin{abstract}
The advent of Covid-19, social isolation and preventive measures against the new coronavirus, it was necessary to suspend face-to-face activities worldwide. Teachers and students migrated to online reality so that classes took place in virtual environments. This context meant that many teachers had to re (learn) to teach remotely. Thus, this research aimed to investigate how teachers developed pedagogical activities, problematizing challenges and difficulties faced during the teaching-learning process. To this end, an online questionnaire was applied to 145 teachers with closed and open questions, which were analyzed in the light of Content Analysis. It was possible to observe that among the main challenges stand out the connection, the appropriation of the digital platforms and the lack of interest of the students. However, even in the face of this, teachers sought ways to overcome difficulties to make remote teaching more interactive, motivating and dynamic.
\end{abstract}

Keywords: Remote education. Covid-19. Pedagogical activities. 


\section{INTRODUÇÃO}

O processo de globalização, de ampliação dos meios de comunicação e do avanço tecnológico tem ocasionado diversas mudanças na sociedade, inclusive no que diz respeito aos cenários de ensino e aprendizagem digital. Silva e Martins (2013) nos dizem que é quase impossível viver sem estarmos conectados a alguma rede de informação e/ou comunicação veiculada pelas tecnologias, seja para estudar, trabalhar ou como forma de entretenimento.

Entretanto, pesquisas têm apontado que o uso dos recursos tecnológicos no ambiente escolar não é garantia de melhoria na qualidade da aprendizagem (SOUSA, 2012; MENDONÇA, 2010; CARMO et al., 2004). O uso de novas ferramentas educacionais requer, portanto, novas metodologias, assim como, novas estratégias de modo que todos esses recursos ganhem sentido em suas abordagens. Em um cenário, onde muitos profissionais da educação ainda possuem dificuldades na incorporação destes recursos em suas práticas, o que se objetiva é superar desafios estabelecendo soluções capazes de nortear o trabalho pedagógico, a fim de que o processo educativo seja desenvolvido de modo satisfatório.

Com a difusão das tecnologias da informação e comunicação, o computador ganhou destaque como recurso auxiliar no processo de construção do saber pelos alunos. A relação pedagógica, que é caracterizada pelo vínculo do ensino e aprendizagem entre professor e aluno, tem um papel significativo com o uso do computador na educação, ou seja, permite consolidar e ampliar a interação e a colaboração entre todos os atores envolvidos no aprendizado. O professor, nesse contexto, assume a postura de colaborador e os alunos são mais participativos. Com isso, os materiais para as aulas são apresentados em novos formatos, com variados recursos, de forma a respeitar o estilo de aprender dos alunos e o nível em que se encontram (MOREIRA, 2018).

Entretanto ninguém, nem mesmo os professores que já incorporam atividades remotas em suas práticas, imaginariam que uma mudança tão rápida e radical nas relações que envolvem o processo de ensino-aprendizagem fosse acontecer em decorrência da disseminação da Covid-19. A UNESCO (2020) estimou um impacto em mais de $70 \%$ da população estudantil no mundo durante o isolamento social, destacando que no pico da pandemia chegou a mais de 1,7 bilhão de estudantes afetados, ou seja, $90 \%$ de todos os estudantes do mundo.

A partir da expansão da Covid-19, dos decretos de isolamento social, das medidas preventivas de combate ao novo coronavírus, a suspensão de atividades presenciais tornou-se inevitável em todo o mundo. Assim, professores e estudantes se viram obrigados a migrar totalmente para a realidade online, sendo necessário transpor práticas presenciais para o ambiente virtual. Desta forma, caracterizou-se o que tem sido chamado de Ensino Remoto Emergencial (ERE). Vale destacar, que esta fase de transição foi marcada por momentos de escolhas, que vão desde a plataforma a ser usada ao material mais adequado para as atividades pedagógicas. Estamos em tempos de aprender a ensinar, ou melhor, reaprender, articulando diversas interseções inerentes à prática docente, tais como: a abordagem didático-pedagógica dos conteúdos, o uso e o domínio dos recursos tecnológicos.

A suspensão das atividades presenciais representou para muitos estudantes uma ruptura no processo de ensino-aprendizagem, visto que mesmo para crianças, adolescentes e jovens que comumente utilizam os meios tecnológicos, há limites para a apropriação dos conteúdos (SENHORAS, 2020). Além do que, na sala de aula é que se tem mais suporte e mais contato com o professor. Nesse sentido, Oliveira e Souza (2020) complementam que a educação, mesmo que ocorrendo à distância, se configura como uma área que necessita do contato diário presencial.

Neste novo cenário, professores se viram obrigados a (re)aprender a lidar com uma variedade de recursos, a gravação de vídeo-aulas, sistemas de videoconferência, como por exemplo, o Zoom e o Hangout, postagem de material didático adaptado para plataformas como Google Classroom. Entretanto, muitas vezes, esses recursos tecnológicos têm sido utilizados apenas em uma perspectiva instrumental, de forma limitada, que acaba reduzindo o ensino a uma prática meramente transmissiva e informativa. 
De acordo com Moreira (2018) é importante que sejam criados modelos de aprendizagem em espaços virtuais que promovam um ambiente de aprendizado colaborativo e dialógico. Mas nesse momento de pandemia, onde as práticas sociais e educativas foram abruptamente alteradas, é importante questionarmos: os professores, em sua maioria, sentem-se preparados para essa transição? A partir das medidas emergenciais, os professores tiveram algum tipo de suporte técnico e pedagógico para as atividades didáticas? Como os alunos reagiram neste novo cenário que se configurou? Quais impactos o ERE trouxe para a vida pessoal e profissional dos professores?

Diante destes questionamentos, o presente estudo teve como objetivo investigar como professores, da educação básica a pós-graduação, desenvolveram atividades pedagógicas remotas em tempos da Covid-19. Entendendo assim, os desafios e as dificuldades enfrentados durante o processo de ensino-aprendizagem.

\section{METODOLOGIA}

A presente pesquisa caracterizou-se como de cunho qualitativo, que segundo Bauer e Gaskell (2002) deve ir além da quantificação da opinião dos participantes, explorando as diferentes representações sobre o assunto em questão. Assim, Moraes (2003) afirma que a pesquisa qualitativa busca aprofundar a compreensão dos fenômenos que investiga a partir de uma análise criteriosa das informações coletadas.

Para a coleta dos dados foi elaborado um questionário contendo perguntas fechadas como: gênero, faixa etária, escolaridade, segmento de ensino em que atua, tempo de magistério, esfera da instituição em que trabalha, experência com aulas remotas, suporte dado pela instuição, frequência de participação dos alunos e os recursos tecnológicos utilizados nas aulas. Além destas perguntas, o questionário possuía perguntas abertas acerca das estratégicas pedagógicas utilizadas pelos professores, as dificuldades do ensino remoto, as respostas do alunos a esse novo cenário de ensino, os impactos desta nova realidade na vida dos professores e, ainda, uma ultima questão onde o professor poderia expressar algo que se sentisse a vontade de dizer. No cabeçalho do questionario havia um pequeno texto explicando do que se tratava a pesquisa. Além disso, antes das perguntas tinha a opção do professor não autorizar que suas respostas fossem utitizadas para publicações. Destaca-se que todos autorizaram.

A análise das perguntas abertas foi realizada à luz da Análise de Conteúdo (BARDIN, 2016). Segundo Campos (2004), esta análise pode ser entendida como um conjunto de técnicas de pesquisa com o objetivo de dar sentido ou sentidos aos documentos, como por exemplo, obtidos por entrevistas e questionários.

O questionário foi elaborado utilizando-se o recurso Microsoft Forms e aplicado durante dez dias da primeira quinzena do mês de julho de 2020. Entendendo que neste momento, a maioria dos professores já estavam encerrando as atividades do semestre e teriam melhores condições de refletir sobre o novo cenário de ensino-aprendizagem imposto pela pandemia. O questionário foi acompanhado de um Termo de Consentimento Livre e Esclarecido (TCLE) que autorizava a divulgação dos resultados da pesquisa mantendo a privacidade dos respondentes. Esta pesquisa foi submetida a avaliação do Comitê de Ética em Pesquisa (CEP) por meio da Plataforma Brasil, sendo validada por meio do Certificado de Apresentação para Apreciação Ética (CAAE) de $n^{\circ} 21794619.0 .0000 .5285$.

\section{RESULTADOS E DISCUSSÃO}

Participaram da pesquisa 145 professores da educação básica à pós-graduação. Deste total, 52\% possui entre 36 e 50 anos, $26 \%$ de 20 a 35 anos e $22 \%$ está acima dos 50 anos. A maioria (60\%) é do gênero feminino. Os professores que possuem especialização contabiliza 38\%, já com mestrado 30\%, 16\% tem graduação, $14 \%$ possui doutorado e, $2 \%$ pós-doutorado. No que diz respeito a graduação, a maioria dos professores é de Ciências 
Biológicas. Vale destacar, que havia professores de diferentes áreas do conhecimento, como por exemplo, Direito, Medicina Veterinária, Nutrição, Pedagogia, Farmácia, Educação Artistica, Enfermagem, Fonoaudiologia, Matemática, Química, Geografia, Física, Engenharia, entre outras. Ao analisarmos os cursos de pós-graduação dos professores, foi possível observar que mais uma vez há uma diversidade de áreas, encontrando professores pós-graduados, por exemplo, em Educação, Direito, Saúde, Artes e Meio Ambiente. Em relação ao nível de ensino, 30\% atua no Ensino Médio, 27\% no Ensino Fundamental II, 20\% no Fundamental I, 20\% no Ensino Superior e 3\% na Pós-graduação.

Dada a variedade de áreas de formação dos professores, as disciplinas ministradas traduziram a mesma realidade, visto que encontramos ciências, biologia, quimica, desenho, direito penal, saúde coletiva, artes, matemática, bioquímica, zoologia, etc. Interessante destacar que com essa amostra de professores de diferentes áreas, atuando em diferentes níveis de ensino e com diferentes disciplinas criamos um momento para reflexão de diferentes práticas e com diferentes públicos o que torna o estudo mais diverso e enriquecedor.

Outro dado levantado foi em relação a instituição em que os docentes atuam, encontramos que a maioria (55\%) são de instituição pública, da esfera municipal. No que diz respeito ao tempo de magistério, 44\% possui mais de 15 anos, 44\% entre seis e quinze anos e, $12 \%$ tem entre um e cinco anos de experiência docente, ou seja, a maioria dos professores possui mais de seis anos de magistério.

Quando questionados se já tinham minstrado aulas remotas, 86\% afirmou nunca ter tido esta experiência. Esse dado nos chama atenção para o fato de que mesmo se tratando de tecnologia para o ensino, os professores ainda não tinham vivenciado na prática. Entretanto, 51\% dos docentes afirmaram se sentir preparados para trabalhar de forma remota. Nesse sentido, Alves (2018) afirma que muitos docentes, mesmo com dificuldade em usar recursos tecnológicos, procuram inserí-los em suas práticas como forma de atender melhor os alunos que já fazem uso habitual destes recursos.

Avançando no entendimento de como se deu a aproximação dos professores com o ERE perguntamos se tiveram algum tipo de suporte técnico e pedagógico da instituição em que atuam. Interessante destacar, que $55 \%$ afirmou ter recebido suporte por parte da escola e/ou faculdade onde lecionam. O notebook foi o equipamento mais utilizado pelos professores (81\%), $13 \%$ o celular, $4 \%$ o desktop e, apenas $2 \%$ optaram por usar o tablet para as aulas remotas.

No sentido de compreender como foi a participação dos alunos nas atividades remotas, perguntamos ao docentes sobre a frequencia e, a maioria (78\%) afirmou que os alunos participaram menos das aulas remotas que quando têm aulas presenciais. Esse dado torna-se relevante no sentido de pensar propostas pedagógicas adaptadas aos espaços virtuais que promovam uma aproximação com os alunos, contribuindo para maior adesão (MOREIRA, 2018).

Na segunda parte do questionário buscamos entender as estratégias utilizadas no ERE, como os alunos respondiam a esta situação, as dificuldades dos professores e os impactos das atividades remotas na vida pessoal e profissional. Nesta etapa, as análises foram fundamentadas a partir da criação de categorias a posteriori de acordo com Bardin (2016). Para ilustrar e ampliar a discussão, optamos por apresentar algumas falas de percepção dos professores sobre aprender e reaprender a ensinar em tempos de isolamento social.

No que diz respeito a categoria estratégias didáticas, devido a diversidade de respostas, que em muito reflete as realidades dos docentes, foi possível identificar subcategorias, sendo estas: plataforma digital, recursos audiovisuais, midias sociais e material de apoio. Importante destacar que quando dizem plataforma digital, os professores se remetem ao Google Classroom, Microsoft Teams, Canvas e Zoom. Estas foram as mais citadas e, 
segundo os docentes, contribuem para maior interação e proporcionam autonomia para os alunos administrarem os estudos.

Em relação aos recursos audiovisuais os professores afirmam buscar uma variedade de materiais que tornem as aulas remotas mais interativas, dinâmicas e lúdicas, visto que assim conseguem despertar mais o interesse dos alunos. Os vídeos do youtube foram os mais citados pelos professores. Essa experiência é evidenciada nas falas de alguns professores:

\begin{abstract}
"Uso slides coloridos e animados. Muitos vídeos, trechos de filmes e documentários. Muitas vezes uso o Google imagens para ilustrar alguma coisa que os alunos perguntam. Tem que ser assim, se não perdem o interesse.”
\end{abstract}

\begin{abstract}
“Os videos curtos ajudam muito, procuro sempre separar material que desperte o interesse e atenção dos alunos. Mesmo sendo adultos, precisam deste estímulo. Busco explorar várias linguagens, vídeos, músicas, charges. Tudo para tornar as aulas mais interessantes. Tem muitos videos legais e educativos no youtube. Sempre uso!”
\end{abstract}

Interessante observar que mesmo sendo professores que atuam em diferentes niveis de ensino e contextos sociais o uso de recursos audiovisuais assume importante papel no sentido de motivar os alunos e despertar o interesse pelo tema que está sendo trabalhado nas aulas remotas. Conforme exposto por Arroio e Giordan (2006) os recursos audiovisuais possibilitam abordar os conteudos de forma mais interativa e, assim, despertam o interesse do aluno e auxiliam o professor na explicação de conceitos abstratos.

Outra estratégia muito citada pelos professores foram as midias sociais, destacando-se facebook, whastapp e instagram. Segundo os docentes que disseram usar essas midias, os alunos interagem melhor com o grupo e, se sentem mais interessados nas discussões que acontecem durante o ERE. Destacam ainda, que usam essas midias para postar atividades e temas que serão trabalhados nas aulas pela facilidade de acesso dos alunos.

\footnotetext{
"Sempre posto material e dicas no facebook. É incrível, os alunos interagem muito mais! É o que eles curtem mesmo."
}

\begin{abstract}
"Depois que passei a usar mais o facebook, instagram e o zap meus alunos passaram a interagir mais e tiveram mais vontade de participar das atividades.”
\end{abstract}

Na subcategoria material de apoio, muitos docentes sinalizaram que usam slides produzidos no powerpoint, apostilas no formato pdf e textos para leitura. Foi possível observar que mesmo diante de uma diversidade de recursos digitais, alguns professores preferem usar materiais que estimulem a leitura e a criatividade do aluno, seja na produção de desenhos, seja na produção de histórias. Este fato representa o que Moreira e Schlemmer (2020) chamam de paradigma da educação digital, visto que os professores se depararam com uma mudança muito rápida e emergencial, devido ao coronavírus, obrigando-os a transpor metodologias e práticas das aulas presenciais para os meios online. Entretanto muitos ainda lançam mão de materiais típicos da educação presencial.

\footnotetext{
"Procuro sempre textos que despertem neles o desejo de fazer as tarefas, assim como tento despertar o desejo de produzir textos e histórias em quadrinhos com o assunto atual. Assim os incentivo a ler mais.”
}

“Mesmo com tantas tecnologias novas, não abro mão de que os alunos leiam textos. Para mim isso é fundamental, mesmo com aulas remotas. Eles precisam ler, precisam ser criativos. É isso!” 
Depois de compreender quais estratégias pedagógicas os professores têm utilizado no ERE é importante discutir que dificuldades e desafios tiveram que superar durante o processo de ensino-aprendizagem. Assim, foi possível analisar os dados a partir da criação das seguintes categorias: acesso, interação e conexão. No que diz respeito a primeira categoria, os professores apontaram como sendo uma das maiores dificuldades, visto que tanto para eles quanto para os alunos, o acesso às plataformas digitais foi o grande desafio. Essa dificuldade pode estar atrelada ao que Santos et al. (2020) destacam ao afirmarem que para as práticas de letramento digital serem efetivamente contempladas em sala de aula, precisa-se investir em programas de formação continuada de professores no sentido de se apropriarem dos recursos digitais. Outro aspecto relacionado a dificuldade de acesso não remete ao processo de interação com as plataformas mas sim o fato de que nem todos os alunos possuem computador para a acompanhar as aulas e realizar as tarefas solicitadas.

\footnotetext{
“Acesso dos estudantes. Muitos não possuem computador, as vezes apenas um computador para toda a família usar. Muitos não tem a possibilidade de acesso nem mesmo pelo celular. Isso gera desinteresse por parte dos estudantes.”
}

\begin{abstract}
“Atende um grupo mínimo de alunos, a plataforma oferecida é de difícil acesso, poucas famílias apresentam recursos tecnológicos para acessar as aulas.”
\end{abstract}

"Muitos alunos apresentam dificuldades em utilizar o computador e acessar plataforma ou não possuem internet, e por celular sentem grandes dificuldades também."

Além da dificuldade de acesso ao computador e às plataformas, outro aspecto recorrente nas falas dos professores foi a pouca ou nenhuma interação durante as aulas. Este fator é determinante para que de fato o processo de ensino-aprendizagem seja efetivo. Para Vigotsky (2009) a interação e a mediação são aspectos fundamentais no processo educativo, uma vez que estes elementos estão intrinsecamente interligados na formação e desenvolvimento dos sujeitos. Os professores apontaram que em muitos momentos não tinham certeza que o aluno estava presente na aula. Além do que, muitos docentes consideram o contato físico, a aproximação entre docente e aluno como aspectos essenciais na aquisição de conhecimento. Isso é mais percebido por alguns docentes, que destacam, por exemplo, ser muito difícil ensinar matemática e desenho de modo remoto.

"A dificuldade de não poder acompanhar os alunos de perto nas tarefas e na matemática, dificuldade de explicar o conteúdo, pois precisam muito do concreto. Preciso estar perto deles para perceber como estão.”

\begin{abstract}
“Alunos pouco participativos com câmera e áudio desligados, não permitindo saber se o aluno de fato está acompanhando a aula ou se está conseguindo acompanhá-la e compreendendo o conteúdo. Além disso, a interação de forma remota é limitada dificultando a proximidade com os alunos e não permitindo certas percepções que só podem ser tiradas olhando nos olhos.”
\end{abstract}

"Falta de proximidade física com o aluno que impede uma melhor percepção do semblante do aluno, onde é muitas vezes é possível perceber se o conteúdo está sendo ou não entendido. ”

A maior dificuldade apontada pelos professores se enquadra na categoria conexão. A partir dos relatos foi possível observar que este problema é enfrentado tanto por docentes como por discentes. Destaca-se que sem conexão adequada as propostas pedagógicas acabam não acontecendo como planejadas pelos professores, dificultando ainda mais a interação e a participação dos alunos no ERE.

“A conexão não é constante. Quantas vezes no meio da aula, os alunos saem por esse problema. Aconteceu comigo várias vezes. Como ensinar e aprender assim?” 
"Não tendo uma boa conexão. Fica difícil manter a atenção dos alunos e garantir que eles participam. Em duas aulas, minha conexão também caiu e para retomar foi muito difícil.”

Após entendermos as principais dificuldades encontradas pelos professores, foi perguntado como os alunos reagiram ao ERE. A maioria dos docentes afirmou que os alunos apresentaram desinteresse, mesmo os adultos de cursos de graduação e pós-graduação. Foi pontuado ainda, que alunos antes participativos nas aulas presenciais se tornaram apáticos e pouco interagiam com as propostas remotas. Este fato, fez com que os professores buscassem recursos mais interativos e dinâmicos como forma de resgatar o interesse dos alunos pelos conteúdos abordados.

Ainda discutindo a resposta dos alunos vale destacar a fala do professor que não identifica como sendo um problema do aluno ou das aulas, mas sim a abrupta mudança nos hábitos e a falta de apoio da família.

\begin{abstract}
"Eles não tem maturidade para esse tipo de aula, na verdade foi uma mudança muito repentina e os estudantes precisam muito do comprometimento da família para orientá-los e auxiliá-los nas dificuldades. A questão é que nem sempre eles vão ter esse suporte. Precisam ter um ambiente de estudo adequado dentro de casa, como iluminação, mesa etc.”
\end{abstract}

Destaca- se ainda, que alguns professores sinalizaram que no início das aulas remotas os alunos mostraram-se mais participativos, mas com o passar dos dias, a desmotivação e a apatia predominavam na maioria deles.

\footnotetext{
"No começo estavam dispostos. Passadas algumas semanas, nota-se que estão cansados, que se envolvem menos, estão entediados. Fazem poucas perguntas, poucas interações. Isso dificulta muito o processo de ensino-aprendizagem."
}

Esses dados coadunam com estudo de Garcia e Silva 2017) ao identificarem a desmotivação dos alunos como a maior barreira para o ensino remoto.

Um dado interessante foi o fato de alguns docentes do ensino superior da rede privada afirmarem que houve evasão de alunos, muitos trancaram a matricula ou desistiram de algumas disciplinas. Observa-se assim, que estratégias de ERE precisam ser repensadas no sentido de atender a uma demanda de público bastante heterogêneo.

\footnotetext{
"Tenho uma turma muito participativa no particular, muitos trancaram, 90\% dos meus alunos tem grandes dificuldades e não conseguem uma interação eficiente.”
}

\begin{abstract}
"Os meus estão mais desmotivados e desinteressados do que nunca. Quando consigo ativar a curiosidade e o interesse deles, ficam animados e parecem um pouco com o que eram. Mas na aula seguinte são de novo icebergs. Muitos desesperançosos, sem ânimo. Vários já abandonaram algumas disciplinas e outros chegaram a trancar o curso.”
\end{abstract}

Apesar destes aspectos que emergiram das falas dos professores, destacamos que houve alguns relatos de maior participação dos alunos no ERE. Isto se deu, sobretudo, pela proposta de aulas mais interativas e dinâmicas, onde os alunos precisam exercitar a autonomia e a interação com o grupo. Nesse sentido, Marques et al. (2017) inferem que o professor ao propor atividades lúdicas, em aulas remotas, torna o aprendizado mais atrativo e motivador para os alunos. 
“Gostam muito. Procuro sair da mesmice, alternando as estratégias e usando layout diferentes como fundo de tela. Trabalho numa visão mais dialogada e interativa. Utilizo muitos artefatos dinâmicos.”

“Tudo é muito novo. De maneira geral, eles gostam bastante. Acredito que sentem falta do contato e da convivência diária com os colegas e professores. Mas, com o passar do tempo, percebo que eles se adaptaram a nova rotina. Até participam mais das aulas."

Pensando no bem-estar docente, foi questionado acerca dos impactos que o ERE trouxe para sua vida pessoal e profissional. Neste sentido foram criadas as seguintes categorias de análise: formação continuada, sobrecarga de trabalho, problemas físicos e emocionais. No que tange a primeira categoria percebeu-se que os professores assumiram a importância de estarem sempre se atualizando não só no que diz respeitos aos conteúdos científicos da área que lecionam, mas sobretudo sobre as estratégias pedagógicas. Perceberam que neste momento de pandemia, com a implementação abrupta do ERE foi necessário lançar mão de conhecimentos que não foram adquiridos em cursos de formação, sendo este aspecto um dos mais desafiadores para as atividades com os alunos.

\footnotetext{
“Acredito que apesar dos grandes desafios nesses quase 4 meses, considero que reinventei minhas práticas docentes. Aprendi usar ferramentas digitais que não tinha utilizado antes. Produzi vídeos caseiros para aulas. Por que não fiz isso antes?”
}

"Mudança total de paradigmas, perda do medo do uso das tecnologias, um olhar mais aberto quanto ao espaço virtual. Hoje quero aprender mais sobre tecnologias no ensino".

“A importância em investirmos em formação continuada e aprimorarmos as formas de ensino. Percebi com tudo isso que não podemos parar no tempo".

Apesar de alguns professores entenderem esse momento como propício para reflexão acerca da importância de formação continuada, sobretudo em relação ao uso de tecnologias no ensino, esta não foi a categoria mais representativa do estudo. Já que a maioria dos professores apontaram que o ERE trouxe impactos para a qualidade das aulas, devido a uma sobrecarga de trabalho. Isto se justifica pela necessidade de tempo que tiveram para entender o universo do uso de tecnologias, adequação do conteúdo para as plataformas digitais e, demanda de reuniões e outras atividades que surgiram com o passar dos meses. Percebe-se que para muitos, estes aspectos chegaram a comprometer a qualidade do trabalho que estavam realizando. Garcia e Silva (2017) em estudo de percepção dos professores sobre ensino remoto também identificaram que uma das maiores barreiras para este modelo é o aumento do tempo de trabalho.

\footnotetext{
“Além de aumentar muito a quantidade de horas trabalhadas, nos fez reformular todo o processo de ensino-aprendizagem. Tivemos que aprender muitas coisas sem querermos, sem termos condições de aprender naquele momento.”
}

"Excesso de trabalho. Creio estar trabalhando mais pois vou muito além do horário de trabalho. Não que professores já não façam isso, diários, correções, preparo de aulas, etc. mas a forma remota parece exigir ainda mais tempo. Percebo que meu rendimento caiu muito.”

Entretanto a categoria mais recorrente diz respeito aos impactos a saúde dos professores. A maioria relatou que vão desde aspectos físicos como dores no corpo e cansaço até problemas emocionais. Há relatos que destacam o ERE como precursor de uma série de problemas como fobias, ansiedade e estresse. 
Já passei mal, desenvolvi fobias, tive crises de ansiedade.

A sensação que tenho é a de que minha vida pessoal foi invadida pela profissional. Minha casa deixou de ser meu local de descanso para ser meu local de trabalho. Isso me provocou um cansaço físico, sinto muitas dores. Sem falar no emocional, meu humor tem oscilado muito. Acho que é mesmo estresse."

Finalizando o questionário, foi deixado um espaço livre para o professor escrever o que desejasse. Vale destacar que, mesmo sendo opcional, 90\% usaram esse momento para complementar e até mesmo trazer questões não abordadas anteriormente. Infere-se com esse dado, sobre a necessidade do professor de compartilhar e trocar experiências sobre os momentos de adaptação para o ERE. Dentre os aspectos mais recorrentes foi o receio do retorno às aulas presenciais sem a produção de uma vacina contra o coronavírus. Também mencionaram a importância da democratização do ensino, visto que nem todos os alunos tiveram acesso à internet de qualidade e, consequentemente surgiram inúmeras dificuldades para acompanhar as aulas. Apesar de todas as dificuldades, alguns professores expressaram as mudanças que a pandemia impôs às práticas pedagógicas, ou seja, a necessidade de re(aprender) a ensinar em tempos remotos. E, ainda, a superação dos obstáculos por amor aos alunos e ao ato de ensinar, de compartilhar conhecimento.

"Estou me especializando cada vez mais quanto aos recursos tecnológicos educacionais. Temos hoje um treino para o que será a educação no futuro! Juro que quero aprender mais por amor aos meus alunos. Amo ensinar!”

\footnotetext{
"Acho fundamental que neste momento de pandemia e adaptação às aulas remotas, professores e coordenação reavaliem suas atuações, sensibilizando-se para uma questão mais humana, enxugando o conteúdo de abordagem dos temas, contextualizando o momento que se passa com suas matérias e repensando em novas formas de avaliação: mais reflexivas e menos conteudistas. Temos que nos reinventar."
}

O professor ao terminar sua fala dizendo ser necessário se reinventar denota o sentimento que traduz alguns aspectos inerentes à prática docente, como muitas vezes a falta de condições apropriadas, a heterogeneidade dos alunos que chegam a sala de aula, a formação docente, entre outros. Mesmo em um momento tão delicado como o da Covid-19 percebemos o professor buscando formas, estratégias e metodologias que permitam realizar um trabalho de qualidade.

\section{CONSIDERAÇÕES FINAIS}

A motivação para realizar esta pesquisa surgiu com a necessidade de entender questões relacionadas ao ensino remoto imposto pela pandemia da Covid-19. Com os dados podemos problematizar os desafios encontrados por professores e alunos em um novo contexto de ensino-aprendizagem que se apresenta.

Discutir aspectos como dificuldade para adequar as aulas em recursos tecnológicos, resposta dos alunos ao ERE, impactos na vida profissional e pessoal dos professores torna-se cada mais relevante no sentido que estamos diante de uma situação que perdura mais que o esperado no início da pandemia no Brasil. Desta forma, este estudo traz contribuições para se repensar a prática docente em plataformas de ensino remoto, para a necessidade da formação continuada, incluindo a incorporação de recursos tecnológicos em suas práticas. Sinaliza ainda, para a importância de novas pesquisas no sentido de aprofundar os novos contextos de ensino-aprendizagem. Reforçando o esforço de muitos docentes a re(aprender) a ensinar. 


\section{REFERÊNCIAS}

ALVES, L. M. Gamificação na educação: aplicando etodologias de jogos no ambiente educacional. Joinvile: Clube dos Autores, 2018.

ARROIO, A.; GIODAN, M. O Vídeo Educativo: Aspectos da Organização do Ensino. Química Nova na Escola, n. 24, p. 9-11, 2006.

BARDIN, L. Análise de conteúdo: edição revista e ampliada. São Paulo: Edições 70, 2016.

BAUER, M.W.; GASKELL, G. Pesquisa qualitativa com texto, imagem e som: um manual prático. 13ed., Petrópolis, Ed. Vozes, 2015.

CAMPOS, C. J. G. Método de análise de conteúdo: ferramenta para a análise de dados qualitativos no campo da saúde. Revista Brasileira de Enfermagem, v.57, n.5, p.11-24, 2004.

CARMO, B. B. T.; SARAIVA JUNIOR, A. F; CARVALHO, A. C., B. D., RODRIGUES, M. V. Grupo de estudos: uma experiência de melhoria na qualidade da aprendizagem. Anais... XXXII Congresso Brasileiro de Educação em Engenharia, Brasília, 2004.

GARCIA, F. A. N.; SILVA, R. G. O desafio dos professores na conquista de novos saberes para as aulas no ensino a distância. Projectus, v.2, n. 3, p.118-135, 2017.

MARQUES, A. P. A. Z. et al. Team based learning: uma metodologia ativa para auxilio no processo de aprendizagem. Colloquium Humanarum, v. 14, n. esp., p.699-707, 2017.

MENDONÇA, S. G. L; BARBOSA, R. L.L., VIEIRA, N. R., Núcleos de Ensino da Unesp: memórias e trajetórias. São Paulo: Cultura Acadêmica: Universidade Estadual Paulista, Pró-reitoria de Graduação, 2010.

MORAES, R.; GALIAZI, M.C. Análise textual discursiva: processo reconstrutivo de múltiplas faces. Ciência e Educação, v.12, n.1, p.117-128, 2006.

MOREIRA, J.A.M. Transitando de um ensino remoto emergencial para uma educação digital em rede, em tempos de pandemia. Dialogia, n.34, p. 351-364, 2018.

MOREIRA, A., J.; SCHLEMMER, E. Por um novo conceito e paradigma de educação digital onlife. Revista UFG, v.20, n.26, p. 12-30, 2020.

OLIVEIRA, H.V.; SOUZA, F.S. Do conteúdo programático ao sistema de avaliação: reflexões educacionais em tempos de pandemia (COVID-19). Boletim Conjuntura, v.2, n.5, p.12-24, 2020.

SANTOS, J.C.A.; SOARES, L.R.; SORTE, P.B. Letramentos digitais na formação contínua de professores. Revista Teias, v.20, p.1-21, 2020.

SENHORAS, E.M. Coronavírus e Educação: análise dos impactos assimétricos. Boletim Conjuntura, v.2, n.5, p. 34-46, 2020.

SILVA, F. O. C; MARTINS, A.M.D.S.G. F. Uso de aplicativo educacional como reforço no ensino aprendizagem da língua inglesa. In: Os desafios da escola pública Paranaense na perspectiva do professor PDE. Cadernos PDE, 2013.

SOUSA, A. L. C. A importância do trabalho com recursos auxiliares no processo de ensino e aprendizagem de geografia. Monografia. Licenciatura em Geografia. UNB, 2012. 
UNESCO - United Nations Educational, Scientific and Cultural Organization. COVID-19 Educational Disruption and Response. UNESCO. 2020. Disponível em: https://en.unesco.org/covid19. Acesso em: 25/07/2020.

VIGOTSKI, L. S. A construção do pensamento e da linguagem. São Paulo: Editora WMF Martins Fontes, 2009. 